\title{
On the Origin of the Chloramphenicol Resistance Transposon Tn9
}

\author{
By SHIGERU IIDA \\ Department of Microbiology, Biozentrum, University of Basel, Klingelbergstrasse 70, \\ CH-4056 Basel, Switzerland
}

(Received 11 August 1982; revised 25 September 1982)

\begin{abstract}
The widely studied chloramphenicol resistance $\left(\mathrm{Cm}^{r}\right)$ transposon $T \mathrm{n} 9$ came from phage $\mathrm{P} 1 \mathrm{Cm} 0$. This phage, however, had acquired its $\mathrm{Cm}^{\mathrm{r}}$ marker from the $\mathrm{R}$ plasmid pSM14. The analysis of the physical structure of pSM14 has now revealed that this plasmid already carried $\operatorname{Tn} 9$ and also the tetracycline resistance transposon Tn10. Physical and functional studies indicated that Tn9 of pSM14, although capable of transposition, probably translocated to the P1 genome by reciprocal recombination processes.
\end{abstract}

\section{INTRODUCTION}

The chloramphenicol resistance $\left(\mathrm{Cm}^{r}\right)$ transposon $\mathrm{Tn} 9$ is one of the most extensively studied transposons. It is $2638 \mathrm{bp}$ long and includes two flanking directly repeated IS1 elements (MacHattie \& Jackowski, 1977; Alton \& Vapnek, 1979). The gene cat for $\mathrm{Cm}^{\mathrm{r}}$ is carried in the 1102 bp central DNA segment and codes for chloramphenicol acetyltransferase which is also responsible for resistance to fusidic acid (Alton \& Vapnek, 1979; Shaw et al., 1979; Völker et al., 1982). Transposition of $\mathrm{Tn} 9$ was first demonstrated from bacteriophage $\mathrm{P} 1 \mathrm{Cm} 0$ (originally called P1CM) to phage $\lambda$ (Gottesman \& Rosner, 1975). Transposition experiments were later carried out using either $\mathrm{P} 1 \mathrm{Cm} 0$ or $\lambda:: \mathrm{Tn} 9$ as donor genomes (Bukhari \& Froshauer, 1978; Johnsrud et al., 1978; Galas et al., 1980).

Phage P1Cm0 was originally isolated by Kondo \& Mitsuhashi (1964) as a plaque-forming, specialized $\mathrm{Cm}^{\mathrm{r}}$ transducing phage from a P1 lysate prepared from cells harbouring the $R$ plasmid pSM14 (originally named R14). It was thus assumed that transposition of $\mathrm{Tn} 9$ from pSM14 into the P1 genome produced P1Cm0 (Campbell et al., 1977). However, subsequent physical analysis of the $P 1$ and $P 1 C m 0$ phage genomes revealed that PI DNA contains an ISI as a natural constituent, the location of which coincides with that of Tn9 on P1Cm0 DNA (De Bruijn \& Bukhari, 1978; Iida et al., 1978; Iida \& Arber, 1979). Transposition was thus not necessarily involved in the formation of $\mathrm{P} 1 \mathrm{Cm} 0$, which might rather have resulted from restructuring processes including reciprocal recombination between IS1 elements and IS1mediated deletion formation. These processes were shown to have been involved in the formation of a family of IS1-mediated $\mathrm{Cm}^{\mathrm{r}}$ transposons (Arber et al., 1978; Iida \& Arber, 1980; Iida et al., 1980; Iida et al., 1981 a). Furthermore, de novo genesis of IS1-flanked $\mathrm{Cm}^{\mathrm{r}}$ transposons (e.g. Tn2651) with structures similar to that of $\mathrm{Tn} 9$ was demonstrated using a $\mathrm{Cm}^{\mathrm{r}}$ segment on a plasmid containing no IS1 sequence, and the resident IS1 of phage P1 (Iida et al., 1980).

These observations prompted me to suspect that pSM14 might not necessarily carry $\operatorname{Tn} 9$ and that $\operatorname{Tn} 9$ might have its origin in the derivation of the $\mathrm{P} 1 \mathrm{Cm} 0$ genome. Experimental evidence shows that this hypothesis is not correct and that Tn9 is already carried on pSM14 from which it is able to transpose as a unit. These results indicate that $\mathrm{P} 1 \mathrm{Cm} 0$ was formed by two successive recombinations between IS1 sequences of P1 and of pSM14. Indeed, P1Cm, the genome structure of which is identical to that of $\mathrm{P} 1 \mathrm{Cm0}$, were repeatedly isolated from cells carrying both $\mathrm{P} 1$ and pSM14. The structural analysis also revealed that pSM14 is a relative of the $\mathrm{R}$ plasmid R100 (or NR1) and carries the tetracycline resistance ( $\mathrm{Tc}^{\mathrm{r}}$ ) transposon $\mathrm{Tn} 10$ and IS2. 
Table 1. Properties of bacteria, bacteriophages and drug resistance plasmids

Nomenclature is according to Bachmann \& Low (1980), Campbell et al. (1977) and Novick et al. (1976).

Bacteria

\section{ML4}

ML40

WA921

E. coli $\mathrm{O}-26$ (pSM14)

E. coli $\mathrm{K} 12(\mathrm{~F})(\mathrm{pSM} 14)(\lambda)$

R Plasmids

R100-1

$\mathrm{R} 1-d r d 19$

pSMl4

pSHI 158

Phages

P1cits 225

Pl-15clts225 P1-15 hybrid 2, carrying no IS1

PlCm0

$\lambda \mathrm{r} 14::$ IS 1

$\lambda \mathrm{r} 32::$ IS 2
E. coli $\mathrm{K} 12\left(\mathrm{~F}^{-}\right)$thr leu met thi $h s d_{\mathrm{K}}$

$\mathrm{Cm}^{r} \mathrm{Sm}^{r} \mathrm{Su}^{r} \mathrm{Hg}^{r} \mathrm{Tc}^{r} \mathrm{Tra}^{+}$IncFII

$\mathrm{Cm}^{r} \mathrm{Sm}^{r} \mathrm{Su}^{r} \mathrm{Ap}^{r} \mathrm{Km}^{\mathrm{r}} \mathrm{Tra}^{+}$IncFII

$\mathrm{Cm}^{r} \mathrm{Te}^{r} \mathrm{Tra}^{+}$IncFII

$\mathrm{Ap}^{\mathrm{r}} \mathrm{Cm}^{\mathrm{r}}$, pBR327 derivative

Carrying IS 1

Carrying one copy of $\operatorname{Tn} 9$

Used as IS1 probe

Used as IS2 probe
Source/Reference

From H. Hashimoto (Kondo et al., 1962)

From H. Hashimoto (Kondo et al., 1962)

Wood (1966)

Egawa \& Hirota (1962)

Meynell \& Datta (1967)

Kondo et al. (1962)

This study

Scott (1968); lida et al. (1978)

Iida et al. (1980)

Kondo \& Mitsuhashi (1964); Iida \& Arber (1979)

Hirsch et al. (1972)

Hirsch et al. (1972)

\section{METHODS}

Microbial strains and media. The Escherichia coli strains, plasmids and bacteriophages used are listed in Table 1. Growth media were as described previously (Iida \& Arber, 1977; Iida, 1980).

Transduction and isolation of P1-15::Tn9 phages. The general procedures for transduction and isolation of plaque-forming specialized P1 phage derivatives were those described by Iida \& Arber (1977). For the isolation and determination of the frequency of formation of P1-15::Tn9 phages, phage P1-15 was prepared by heat induction of strain ML40 made lysogenic for P1-15clts225. The resulting lysate served to infect strain WA921 at a multiplicity of about 0.03 plaque-forming phages per cell. $\mathrm{Cm}^{r}$ transductants appeared with a frequency of about 2 $\times 10^{-6}$ per plaque forming phage. In each experiment, $30 \mathrm{Cm}^{\mathrm{r}}$ transductants were screened for $\mathrm{Cm}^{\mathrm{r}}$ and $\mathrm{Tc}^{\mathrm{s}}$ phenotypes and for the ability to produce high frequency $\mathrm{Cm}^{r}$ transducing lysates. About half of the $\mathrm{Cm}^{\mathrm{r}}$ transductants usually fulfilled these criteria. Thus, the frequency of formation of $\mathrm{P} 1-15 \mathrm{Cm}$ phages can be estimated as $10^{-6}$ per plaque-forming phage. The genome structure of P1-15::Tn9 was confirmed by restriction cleavage analysis (Iida \& Arber, 1980). P1-15::Tn10 and P1Cm phages were isolated similarly.

Physical analysis of pSM14. Isolation of plasmids, construction of restriction cleavage maps and Southern hybridization of restriction fragments were performed as described before (Southern, 1975; Iida, 1980; Iida \& Arber, 1980). Restriction enzymes were purchased from Boehringer (Mannheim, F.R.G.) or from New England Biolabs (Massachusetts, U.S.A.).

Construction of the pBR327 derivative pSHI158. Plasmid pSM14 was digested with HindIII and BglII and the $\mathrm{Cm}^{r}$ fragment was cloned into the HindIII-BamHI region of the plasmid pBR327 (Soberon et al., 1980).

DNA sequencing. This was done by the method of Maxam \& Gilbert (1977).

\section{RESULTS}

\section{Origin of the $R$ plasmid pSM14}

The R plasmid pSM14, originally called R14, was isolated by K. Ochiai from Shigella flexneri $3 \mathrm{~b} \mathrm{~N}-1$, a strain conferring resistance to $\mathrm{Cm}$, tetracycline (Tc) and sulphonamide (Su) (Kondo et al., 1962). Only the $\mathrm{Cm}^{\mathrm{r}}$ and $\mathrm{Tc}^{\mathrm{r}}$ characters were shown to transfer to $S$. flexneri $3 \mathrm{a} 87$ and then to E. coli O-26 and E. coli K12 (Kondo et al., 1962). Strain ML4 is such an E. coli O-26 (pSM14) transconjugant (H. Hashimoto, personal communication). From an E. coli K12 (pSM14) transconjugant, the $\mathrm{Cm}^{\mathrm{r}}$ and $\mathrm{Tc}^{r}$ markers were transduced with bacteriophage $\mathrm{P} 1$ to an $\mathrm{F}^{+}$strain of $E$. coli $\mathrm{K} 12$ and $\mathrm{Cm}^{r} \mathrm{Tc}^{\mathrm{r}}$ transductants, which were able to transfer both the $\mathrm{Cm}^{\mathrm{r}}$ and $\mathrm{Tc}^{\mathrm{r}}$ markers further into a recipient by conjugation, were isolated (Kondo et al., 1962). Strain ML40 is such a $\mathrm{Cm}^{r} \mathrm{Tc}^{r}$ transductant (H. Hashimoto, personal communication). The $\mathrm{Cm}^{\mathrm{r}} \mathrm{Tc}^{\mathrm{r}}$ plasmids from ML4 and ML40 are now shown to be incompatible with the R plasmid R1-drd19 (data not presented), indicating that pSM14 belongs to the incompatibility group FII. Plasmid pSM14 also confers fusidic acid resistance. 


\section{Restriction cleavage analysis of pSM14}

Plasmids isolated from strains ML4 and ML40 were cleaved with restriction endonucleases and the cleavage patterns were compared with those of R100-1 and F (Ohtsubo \& Ohtsubo, 1977; Iida, 1980). As Fig. 1 shows, ML4 yielded a pure plasmid preparation of pSM14, while the pattern of restriction fragments of plasmids obtained from ML40 points to a mixture of pSM14 and the Inc FI plasmid F. The relative intensity of the fragments produced from pSM14 and F suggests that the copy number of pSM14 in strain ML40 is approximately 2-3 times higher than that of F. The pSM14 plasmids from ML4 and ML40 yielded identical cleavage patterns, indicating that no genetic rearrangement had taken place during conjugation and transduction. Therefore, the physical structure of pSM14 in these strains is likely to be the same as that in the original $S$. flexneri strain.

The restriction cleavage maps of pSM14 (Fig. 2a) were constructed by comparing the cleavage patterns of pSM14 with those of $\mathrm{R} 100-1$, for which restriction cleavage maps exist (Iida, 1980). From the analysis illustrated in Fig. 1, slots 1-3, it was concluded that EcoRI fragments derived from the RTF part of R100-1 are identical to those from pSM14 except for the R100-1 fragments EcoRI-c and EcoRI-h. The pSM14 fragment EcoRI-B corresponds to R100-1 fragment $E c o$ RI-c, but it carries a $1.3 \mathrm{~kb}$ insertion which contains one additional HindIII site. Cleavage at this HindIII site produced pSM14 fragments HindIII-A and HindIII-C which correspond to the R100-1 fragment HindIII-a (Fig. 1, slots 5 and 6). This $1.3 \mathrm{~kb}$ insertion on pSM14 was tentatively assigned as insertion sequence IS 2 , since two fragments from EcoRI-B produced by EcoRI-HindIII double digestion hybridized with the ${ }^{32} \mathrm{P}$-labelled IS2 probe $\lambda \mathrm{r} 32:$ : IS2 (data not shown). IS2 is $1327 \mathrm{bp}$ long and carries one HindIII site $871 \mathrm{bp}$ from one end (Ghosal et al., 1979). The location of IS2 in Fig. 2 is based on this HindIII site and it includes an ambiguity of about $0.4 \mathrm{~kb}$ depending on the orientation of the IS2 insertion. An IS2 is also carried in the homologous region of the tra genes of plasmid R6, a relative of R100-1 (Hu et al., 1975; Timmis et al., 1978).

Most of the R100-1 fragments originating from the r-determinant part are absent in pSM14. As Fig. 1 (slots 1-3) indicates, the pSM14 fragment EcoRI-A corresponds to the R100-1 EcoRI-a fragment which includes IS I a and the N-terminal part of the cat gene (Lane \& Chandler, 1977; Arber et al., 1978; Miki et al., 1978; Marcoli et al., 1980). In R100-1, IS1b is contained in the fragment EcoRI-h, while in pSM14, the fragment EcoRI-G as well as the fragment EcoRI-A hybridized with the ${ }^{32}$ P-labelled IS1 probe $\lambda r 14::$ IS1 (data not shown). Instead of the approximately $22 \mathrm{~kb}$ multiple drug resistance r-determinant of R100-1, pSM14 carries a DNA segment of about $4 \mathrm{~kb}$ containing the cat gene and two copies of IS1.

To examine further if pSM14 carries the IS1-flanked Tn9, pSM14 was cleaved with $P_{s t} \mathrm{I}$ and the resulting fragments were hybridized with ${ }^{32}$ P-labelled $\lambda$ r14 : :IS1 DNA (Fig. 1, slots 7-9). Since ISI carries a unique $P_{s t I}$ site, a Tn9-containing plasmid should produce at least three $P_{s t} \mathrm{I}$ fragments hybridizing with the ${ }^{32} \mathrm{P}$-labelled IS1 probe. Of these three fragments, one (the PstI fragment Z) has the same size as the internal Pst fragment of Tn9, indicating that pSM14 indeed carries the $2.6 \mathrm{~kb} \mathrm{Cm}^{\mathrm{r}}$ transposon Tn9 (Fig. 2). One of the other two hybridizable fragments. PstI-Y, is the same size as the ISla-containing fragment produced from R100-1, while the fragment $P$ st I $\mathrm{I} X$ is about $1.5 \mathrm{~kb}$ longer than the corresponding fragment from $\mathrm{R} 100-1$. This additional $1.5 \mathrm{~kb}$ DNA segment was localized within the region common to HindIII-B and Pst I-X fragments (Fig. 2a). This assignment was further confirmed by the analysis of the plasmid pSHI 158 which carried the Tn9 containing HindIII-BglII segment of pSM14 (Fig. $2 b$ ).

\section{DNA sequence of one end of $\operatorname{Tn} 9$ on $p S M 14$}

It has been reported that the ISla of Tn9 transposed from $\lambda$ cam 1 is an IS1 variant and that its DNA sequence has a $G$ to $T$ transversion at position $757,12 \mathrm{bp}$ from the end of the element (Galas et al., 1980). However, the end sequence of this variant ISl was thought to originate from the ISI of phage $\mathrm{Pl}$, because the same sequence alteration was found in another IS1 originating from P1 (Iida et al., 1981 b) and because the Tn9 on $\lambda$ cam 1 was derived from P1Cm0 (Gottesman \& Rosner, 1975). 

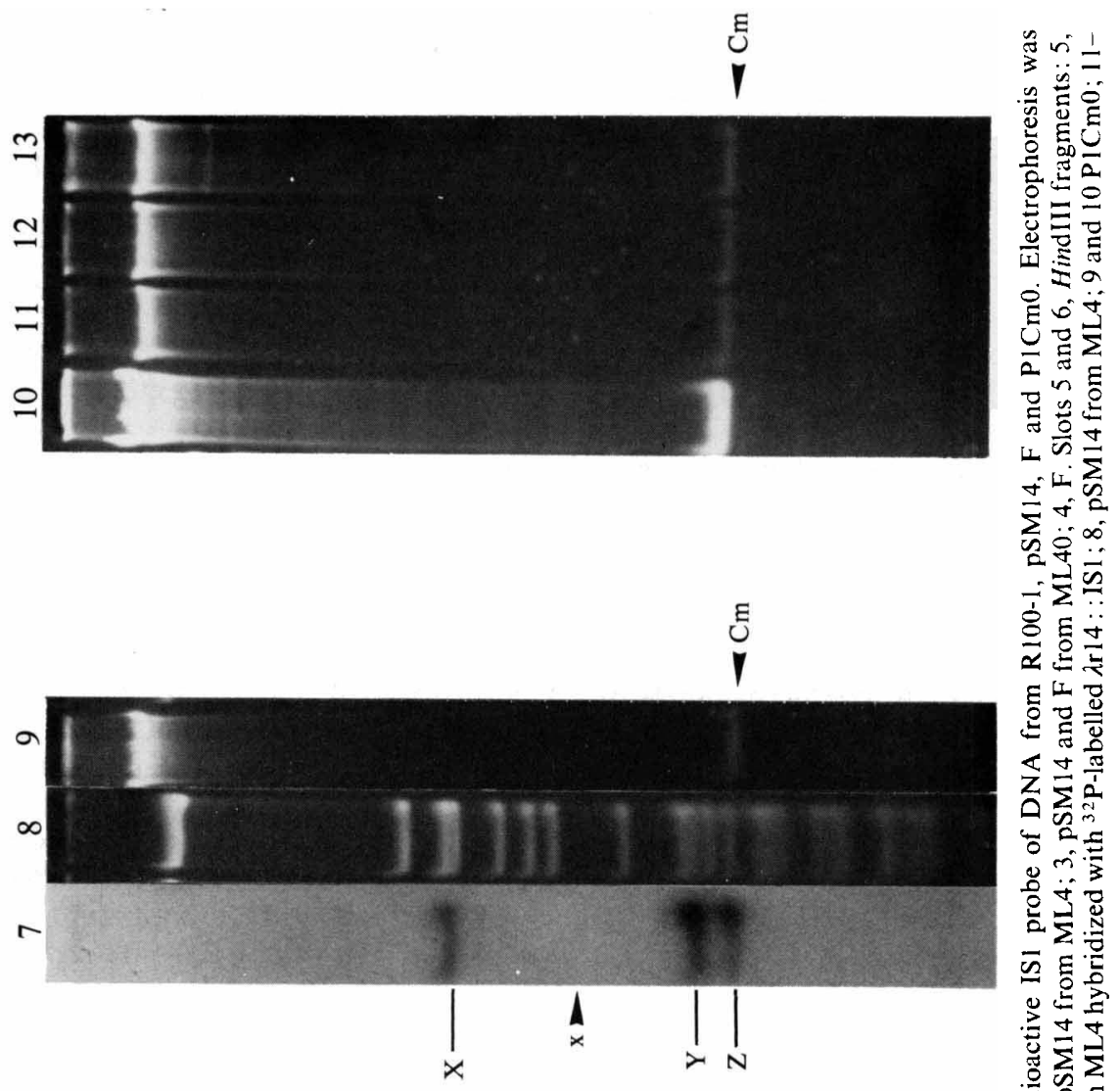

它宫员兽

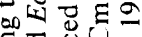

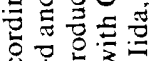

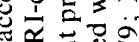
卷苛宗 क्षे

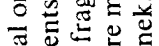

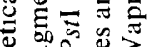

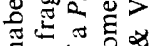
उ 访 和次

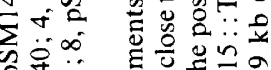

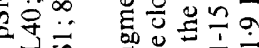

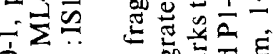

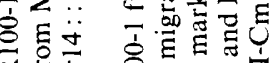

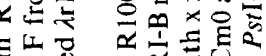

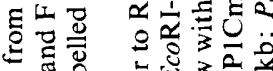
त

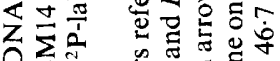
口你

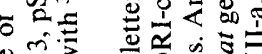
拧 次

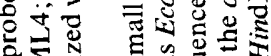

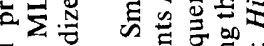

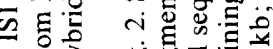

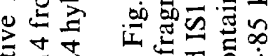

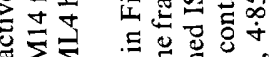

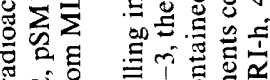

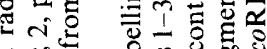

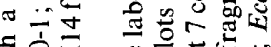

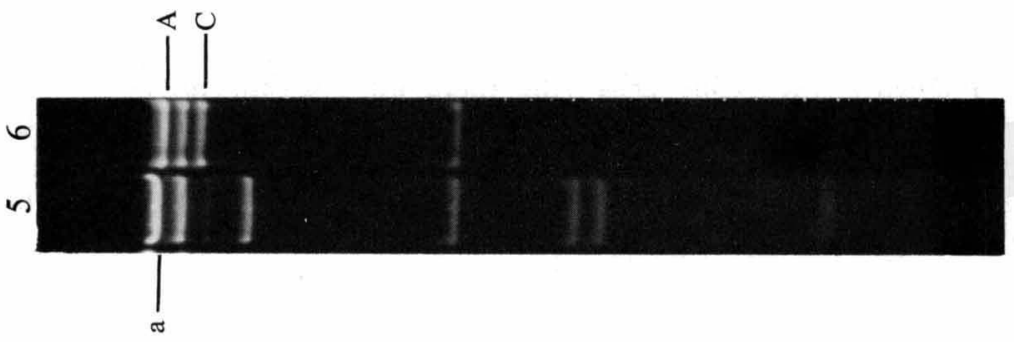

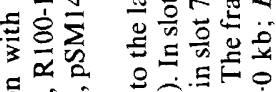
등 $\ddot{0} \ddot{0} \cong$

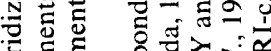
贸

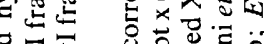

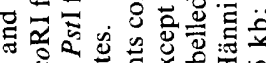

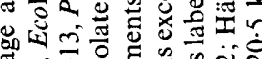
on

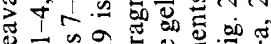

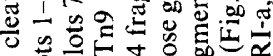
훙 क

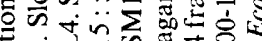

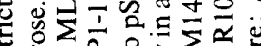

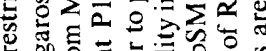

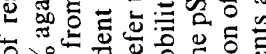

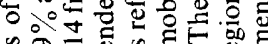

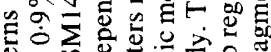

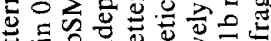

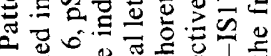
-

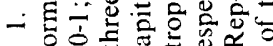

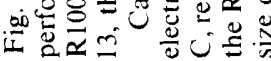




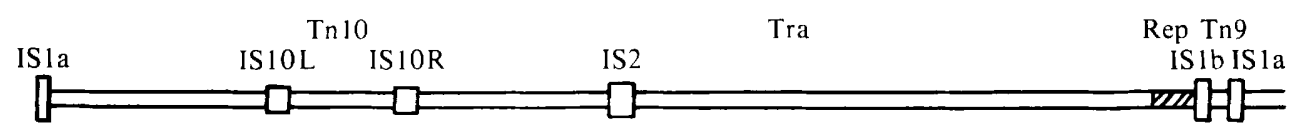

(a)

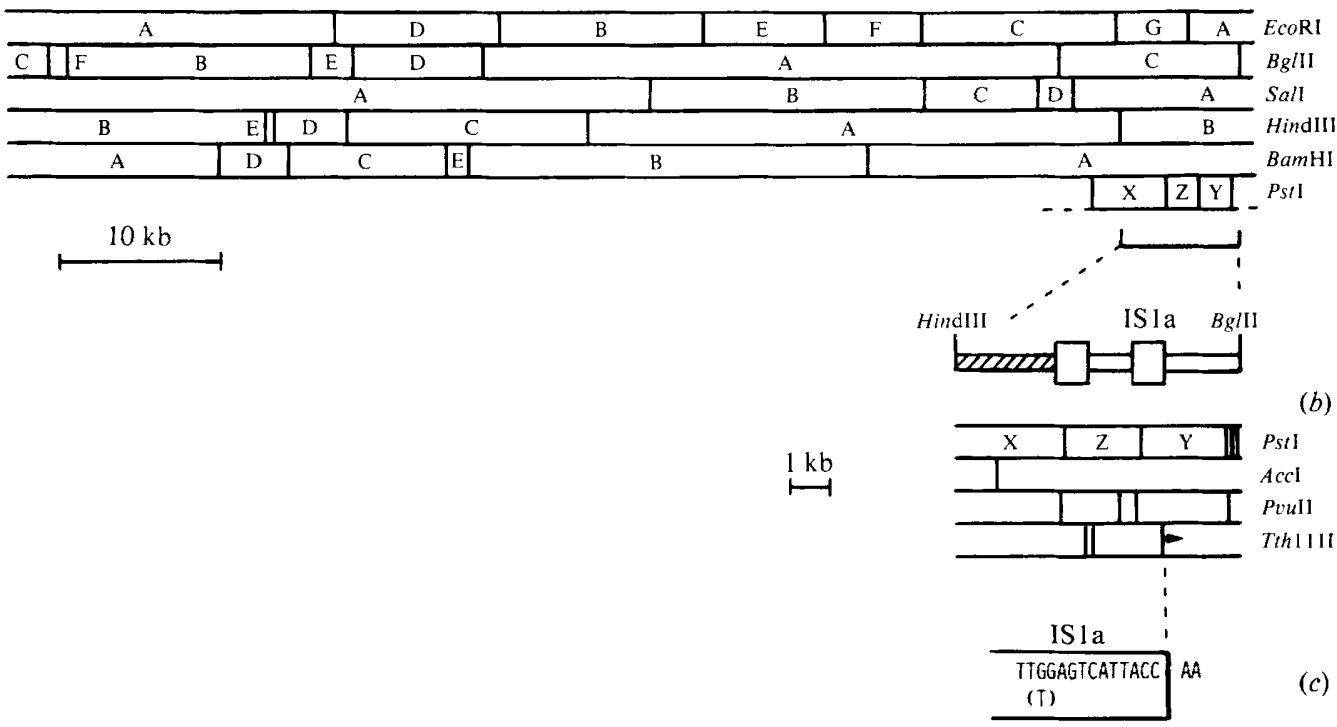

Fig. 2. (a) Restriction cleavage map of the R plasmid pSM14. The circular map is arbitrarily drawn linearly from ISla. The fragments are labelled alphabetically in the order of their electrophoretic mobility in agarose, except for the $P_{s t} \mathrm{I}$ fragments $\mathrm{X}, \mathrm{Y}$ and $\mathrm{Z}$ which contain the IS1 sequences. The indicated locations of IS1, IS10, Tn9, Tn10, Tra and Rep are based on a comparison with the map of R 100-I (Iida, 1980). The shadowed box between a HindIII site and ISIb indicates the DNA segment about $1.5 \mathrm{~kb}$ longer than the corresponding part of R100-1. The bracket under the restriction map represents the $B g / \mathrm{II}-$ HindIII fragment cloned into pBR327 to yield pSHII58.

(b) Restriction cleavage map of the BglII-HindIII fragment containing Tn9. The map is drawn in the same way as $(a)$. The arrow from one Tthl11I site indicates the strategy used to sequence the end of the ISla.

(c) DNA sequence of the end of IS1a. The DNA sequence of the end of IS1a from the Tth111I site (at position 712 of the IS1, 56 bp from the end) is identical to that of IS1b of R100-1 (Ohtsubo \& Ohtsubo 1978). Only the 14 bp sequence at the end of the ISI a sequence and the 2 bp sequence next to the IS 1 are shown. $T$ in parenthesis at $12 \mathrm{bp}$ from the end (at position 757 ) represents the $\mathrm{G}$ to $\mathrm{T}$ transversion found in the ISl variant derived from Pl or from $\operatorname{Tn} 9$ on $\lambda$ caml (Galas et al., 1980; Iida et al., 1981 b).

In order to examine this hypothesis, this end of Tn9 on pSM14 was sequenced. The Tn9containing HindIII-Bg/II fragment of pSM14 was cloned into pBR327. Its restriction sites are shown in Fig. 2(b). The DNA sequence at the end of IS1a on Tn9 in pSM14 was found to be identical to that of IS1b in R100-1 and of IS1b in Tn9 and to be different from that of IS1a on Tn9 which originated from $\lambda c a m 1$ (Fig. 2c; Ohtsubo \& Ohtsubo, 1978; Alton \& Vapnek, 1979; Galas et al., 1980). This result is consistent with the idea that the terminal sequence of Tn9 on $\lambda$ cam 1 is derived from that of the resident IS1 or P1 (Iida et al., 1981b).

Transposition of $\operatorname{Tn} 9$ and Tn10 into the genome of phage P1-15

The restriction enzyme cleavage patterns are consistent with pSM14 being a relative of the $R$ plasmid $\mathrm{R} 100$ (or NR1) and carrying the $\mathrm{Cm}^{\mathrm{r}}$ transposon $\mathrm{Tn} 9$ and the $\mathrm{Tc}^{\mathrm{r}}$ transposon $\mathrm{Tn} 10$. In order to demonstrate that these transposons on pSM14 could transpose normally, plaqueforming derivatives of phage P1-15 showing specialized transduction for either $\mathrm{Cm}^{\mathrm{r}}$ or $\mathrm{Tc}^{\mathrm{r}}$ were isolated as described in Methods. The transposition of $\operatorname{Tn} 9$ and $\operatorname{Tn} 10$ into the P1-15 genome was verified by analysing the DNA of $\mathrm{P} 1-15 \mathrm{Cm}$ and $\mathrm{P} 1-15 \mathrm{Tc}$ phages with restriction enzymes. 

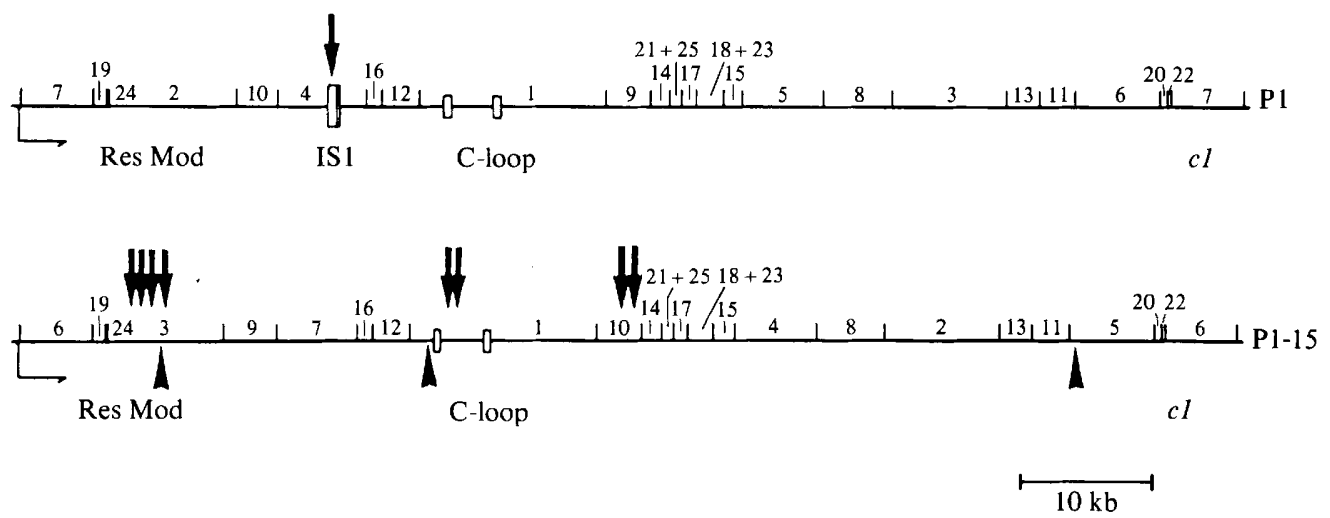

Fig. 3. Sites of insertion of Tn9 and Tn10 on the Pl and P1-15 genomes. Physical maps of P1 and P1-15 are according to Iida et al. $(1981 \mathrm{c})$. Short bars above the lines indicate $E c o$ RI restriction sites and the numbers identify the EcoRI fragments. Phage PI carries an IS1 element (large box) which contains the unique Pst I site of P1 DNA. P1-15 carries neither IS1 nor a PstI site and its genome is about $1 \mathrm{~kb}$ shorter than the Pl genome. The horizontal arrow at the left end indicates the origin and orientation of DNA packaging. The small boxes in the C-loop represent the $0.6 \mathrm{~kb}$ inverted repeats flanking the invertible DNA segments. Res, Mod and $c l$ indicate the locations of genes for restriction, modification and repressor, respectively. Vertical arrows above the map point to independent Tn9 insertion sites. All PICm phages studied carry Tn9 within the residential IS 1 element of Pl. The arrowheads below the PI15 map indicate independent insertion sites of $\mathrm{Tn} 10$. The known restriction cleavage maps for $\operatorname{Tn} 10$ (Jorgensen et al., 1979) and for P1-15 DNA (Arber et al., 1980) served in the determination of these sites.

Transposition frequencies of Tn9 and Tn10 into the P1-15 genome were estimated as $1 \times 10^{-6}$ and $4 \times 10^{-5}$ per plaque forming P1-15 phage, respectively.

In four independent Tn9 transposition experiments, between 10 and $60 \%$ of the $\mathrm{P} 1-15 \mathrm{Cm}$ prophages carried by $\mathrm{Cm}^{r}$ transductants produced no $E c o \mathrm{P} 15$ restriction, i.e. they had a Res(P15)- phenotype. This suggests, in accordance with earlier findings (Meyer et al., 1980), that the Res Mod region of the P1-15 serves as a good target for the transposing Tn9 element. In each of the four experiments, one P1-15Cm Res(P15) ${ }^{+}$and one P1-15Cm Res(P1)- phage was chosen for restriction cleavage analysis. All $\mathrm{Pl}-15 \mathrm{Cm}$ phage genomes had acquired a DNA segment of about $2.6 \mathrm{~kb}$ and the short Pst I fragments derived from these phage DNAs were identical to that from P1Cm0 (Fig. 1, slots 10-13), confirming the P1-15::Tn9 structure of these phages. Since Tn9 carries a single EcoRI site in the cat gene and its two unique PstI sites within the IS1 elements, a comparison of the EcoRI cleavage patterns with those of EcoRI-Pst double digests revealed the locations of the Tn9 insertions (Fig. 3). Finer mapping was done by double digestion with PstI and BamHI, BglII or HindIII, the cleavage sites for which on P1-15 DNA are known (Arber et al., 1980; Iida et al., 1981 c).

For Tn 10 transposition, four $\mathrm{P} 1-15 \mathrm{Tc}$ phages from two independent experiments were chosen and their genome structures were analysed. Three of these were P1-15::Tn10 and their Tn10 integration sites were mapped using the enzymes BamHI, BgIII, EcoRI and HindIII (Fig. 3). The characteristic snap-back structure of Tn10 was observed on the P1-15Tc DNA under the electron microscope (J. Meyer \& S. Iida, unpublished).

One of the P1-15Tc phages studied carries the DNA segment including Tn10 of pSM14 delimited by ISI a and IS10R within the left part of P1-15 EcoRI-2 fragment (data not shown; see also Fig. 2a). One may speculate that this P1-15Tc phage was formed by ISla-mediated transpositional cointegration and subsequent IS10R-mediated deletion formation (Iida \& Arber, 1980; Hänni et al., 1982).

\section{Isolation of PICm phages identical to $\mathrm{PICm0}$}

We have also isolated plaque-forming $P 1 \mathrm{Cm}$ phages in the same way as $P 1-15 \mathrm{Cm}$. The estimated frequency of their formation was $6 \times 10^{-5}$ per plaque-forming P1 phage. Four P1Cm 


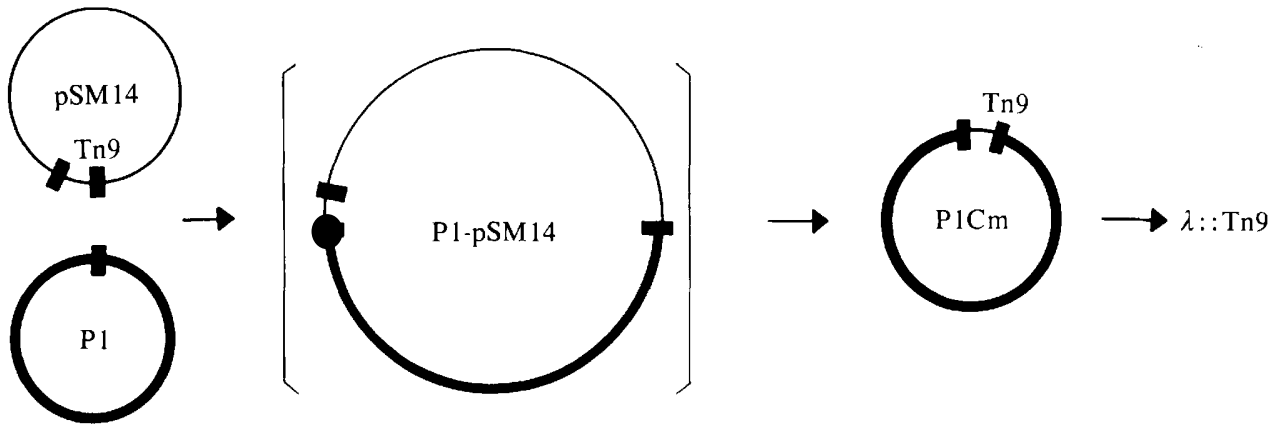

Fig. 4. A putative pathway for the formation of $\mathrm{PlCm} 0$ from $\mathrm{Pl}$ and $\mathrm{pSM} 14$. Reciprocal recombination between IS1 elements is proposed to first form a Pl-pSM14 cointegrate and in a second step the $\mathrm{P} 1 \mathrm{Cm} 0$ genome. Transposition of the $\mathrm{Tn} 9$ from $\mathrm{P} 1 \mathrm{Cm} 0$ to $\lambda \mathrm{DNA}$ yields $\lambda:: \operatorname{Tn} 9$ such as $\lambda$ cam 1 (Gottesman $\&$ Rosner, 1975). The filled boxes represent IS1.

$\operatorname{Res}(\mathrm{P} 1)^{+}$phages from two independent experiments were analysed. They all carried $\operatorname{Tn} 9$ at the site of the residential IS1 of PI DNA (Fig. 3), exactly as is known for P1Cm0. Therefore, P1Cm phages, the genome structure of which is identical to that of $\mathrm{P} 1 \mathrm{Cm} 0$ previously isolated by Kondo \& Mitsuhashi (1964), are repeatedly produced when P1 phage is grown in rec cells harbouring pSM14.

\section{DISCUSSION}

We have shown that the conjugative, incompatibility group FII plasmid pSM14 coding for $\mathrm{Cm}^{\mathrm{r}}$ and $\mathrm{Tc}^{\mathrm{r}}$ carries $\mathrm{Tn} 9$ and $\mathrm{Tn} 10$. The physical structure of pSM14 is similar to that of the wellstudied R plasmid R100 (or NR1). Both R plasmids were originally isolated from $S$. flexneri in Japan (Kondo et al., 1962; Rownd et al., 1966).

Kondo \& Mitsuhashi (1964) isolated a plaque-forming specialized transducing phage $\mathrm{P} 1 \mathrm{Cm} 0$ in experiments involving transduction and conjugation. Phage $\mathrm{P} 1 \mathrm{Cm} 0$ carries $\mathrm{Tn} 9$ at the resident IS1 of $\mathrm{P} 1$. I therefore propose that $\mathrm{P} 1 \mathrm{Cm} 0$ must have been formed by two successive reciprocal recombinations between IS1 elements (Fig. 4). Like the cointegrate P1-R100-20 (Iida, 1980), P1-pSM14 should be a conjugative plasmid as well as a prophage. Therefore, the conjugative transfer of the $\mathrm{Cm}^{r}$ marker with the phage $\mathrm{Pl}$ genome during the isolation of P1Cm0 (Kondo \& Mitsuhashi, 1964) could be reinterpreted as the result of transmission of a PlpSM14 cointegrate. Because of its large size the genome of P1-pSM14 could not be packaged intact into a single $\mathrm{P} 1$ virion. In contrast, the smaller $\mathrm{P} 1 \mathrm{Cm} 0$ segregant genome resulting from reciprocal recombination between two IS1 elements can be packaged as a unit into Pl particles. Thus these form plaques, and this property allows for their easy isolation (Iida, 1980; Iida \& Arber, 1980).

Translocation of $\mathrm{Tn} 9$ from $\mathrm{pSM} 14$ to $\mathrm{P} 1$ was reproducible. Its frequency by processes of reciprocal recombination with the IS1 of $\mathrm{P} 1$ is about 50 -fold higher than that of the transposition of Tn9 from pSM14 to the genome of P1-15, which is largely homologous to P1 DNA, but devoid of an IS1 element. This reciprocal recombination between IS1 sequences depends mainly upon the host $r e c A$ function (Iida \& Arber, 1980; Iida et al., 1981a; Iida et al., 1982).

If the proposed scheme is correct, both ends of $\operatorname{Tn} 9$ on P1Cm0, and therefore also of $\operatorname{Tn} 9$ on $\lambda:: \operatorname{Tn} 9$ (Fig. 4), could have been derived from the ends of the resident ISI element carried on P1 DNA. Sequencing data supported this view and revealed the same base alteration at one end of the IS1 element derived from $\lambda:: \operatorname{Tn} 9$, called $\lambda$ cam 1 , and at the same end of an IS1 which had been transposed from P1 DNA to a small plasmid pBR325 (Galas et al., 1980; Iida et al., 1981 b). Furthermore, this alteration was not found at the corresponding end of IS1a on the original Tn9 in pSM14 (Fig. $2 c$ ).

It is very likely that pSM 14 carried Tn9 already when it was isolated from $S$. flexneri. The true origin of $\operatorname{Tn} 9$ remains unknown. Tn9 could have been produced from a longer $r$-determinant by 
IS1-mediated deletion or it could have been generated by two successive integrations of IS1 elements on either side of the cat gene.

I wish to thank Werner Arber for his encouragement, support and advice in writing the manuscript, Solveig Schrickel and Rosmarie Hiestand for their excellent technical assistance, Hajime Hashimoto for providing strains, Jürg Meyer and Katsutoshi Mise for discussions, and Thomas A. Bickle for reading the manuscript. This work was supported by grant no. 3.479.79 from the Swiss National Science Foundation.

\section{REFERENCES}

Alton, N. K. \& VAPNEK, D. (1979). Nucleotide sequence analysis of the chloramphenicol resistance transposon Tn9. Nature, London 282, 864-869.

ARber, W., IIDA, S., JÜTTE, H., CASPERS, P., MEYER, J. \& HäNNI, C. (1978). Rearrangements of genetic material in Escherichia coli as observed on the bacteriophage P1 plasmid. Cold Spring Harbor Symposia on Quantitative Biology 43, 1197-1208.

Arber, W., Hümbelin, M., Caspers, P., Reif, H. J., IIDA, S. \& MEYER, J. (1980). Spontaneous mutations in the Escherichia coli prophage P1 and IS-mediated processes. Cold Spring Harbor Symposia on Quantitatite Biology 45, 38-40.

BaChMANN, B. J. \& Low, K. B. (1980). Linkage map of Escherichia coli K-12, Edition 6. Microbiological Reviews 44, 1-56.

BUkHARI, A. I. \& Froshauer, S. (1978). Insertion of a transposon for chloramphenicol resistance into bacteriophage Mu. Gene 3, 303-314.

Campbell, A., Berg, D., Botstein, D., LederberG, E., Novick, P., Starlinger, P. \& Szybalskt, W. (1977). Nomenciature of transposable elements in prokaryotes. In DNA Insertion Elements, Plasmids, and Episomes, pp. 15-22. Edited by A. I. Bukhari, J. A. Shapiro \& S. L. Adhya. New York: Cold Spring Harbor Laboratory.

De Bruijn, F. J. \& Bukhari, A. I. (1978). Analysis of transposable elements inserted in the genomes of bacteriophages $\mathrm{Mu}$ and P1. Gene 3, 315-331.

Egawa, R. \& Hirota, Y. (1962). Inhibition of fertility by multiple drug resistance (R) factor in Escherichia coli K 12. Japanese Journal of Genetics 37, 66-69.

Galas, D. J., Calos, M. P. \& Miller, J. H. (1980). Sequence analysis of $\operatorname{Tn} 9$ insertions in the $\operatorname{lac} Z$ gene. Journal of Molecular Biology 144, 19-41.

Ghosal, D., Sommer, H. \& SaEdler, H. (1979). Nucleotide sequence of the transposable DNA element IS2. Nucleic Acids Research 6, 1111-1122.

Gottesman, M. M. \& Rosner, J. L. (1975). Acquisition of a determinant for chloramphenicol resistance by coliphage lambda. Proceedings of the National Academy of Sciences of the United States of America 72, 5041-5045.

HänNi, C., Meyer, J., Iida, S. \& Arber, W. (1982). Occurrence and properties of the composite transposon Tn2672: Evolution of multiple drug resistance transposons. Journal of Bacteriology 150, 1266-1273.

Hirsch, H. J., Starlinger, P. \& BRAChet, P. (1972). Two kinds of insertions in bacterial genes. Molecular and General Genetics 119, 191-206.

Hu. S., Ohtsubo, E., Davidson, N. \& Saedler, H. (1975). Electron microscope heteroduplex studies of sequence relations among bacterial plasmids : identification and mapping of the insertion sequences ISI and IS2 in F and R plasmids. Journal of Bacteriology 122, 764-775.

IIDA, S. (1980). A cointegrate of the bacteriophage P1 genome and the conjugative $\mathrm{R}$ plasmid $\mathrm{R} 100$. Plasmid 3, 278-290.

IIDA, S. \& ARBER, W. (1977). Plaque forming specialized transducing phage $\mathrm{Pl}$ : isolation of $\mathrm{PlCmSmSu}$, a precursor of P1Cm. Molecular and General Genetics 153, 259-269.

IIDA, S. \& ARBER, W. (1979). Multiple physical difference in the genome structure of functionally related bacteriophages $\mathrm{P} 1$ and $\mathrm{P} 7$. Molecular and General Genetics 173, 249-261.

IIDA, S. \& ARBER, W. (1980). On the role of IS1 in the formation of hybrids between the bacteriophage P1 and the R plasmid NR1. Molecular and General Genetics 177, 261-270.

IIDA, S., MEyer, J. \& ARber, W. (1978). The insertion element IS1 is a natural constituent of coliphage Pl DNA. Plasmid 1, 357-365.

IIDA, S., MEYER, J. \& ARBER, W. (1980). Genesis and natural history of IS-mediated transposons. Cold Spring Harbor Symposia on Quantitative Biology 45, $27-43$.

IIDA, S., HÄNNI, C., EChARTI, C. \& ARber, W. (1981 $a$ ). Is the ISI-flanked $\mathrm{r}$-determinant of the $\mathrm{R}$ plasmid NR1 a transposon? Journal of General Microbiology 126, 413-425.

IIDA, S., MARColi, R. \& BickLE, T. A. (1981 b). Variant insertion element IS1 generates 8-base pair duplications of the target sequence. Nature, London 294, 374-376.

IIDA, S., Meyer, J. \& ARber, W. (1981 c). Cointegrates between bacteriophage Pl DNA and plasmid pBR322 derivatives suggest molecular mechanisms for Pl-mediated transduction of small plasmids. Molecular and General Genetics 184, 1-10.

IidA, S., Schrickel, S. \& ARber, W. (1982). On the segregation of IS 1 -mediated cointegrates between bacteriophage P1 DNA and plasmid pBR322 derivatives. FEMS Microbiology Letters 15, 269-273.

Johnsrud, L., Calos, M. P. \& Miller, J. H. (1978). The transposon $\operatorname{Tn} 9$ generates a 9 bp repeated sequence during integration. Cell 15, 1209-1219.

Jorgensen, R. A., Berg, D. E., Allet, B. \& REZNIKOFF, W. S. (1979). Restriction enzyme cleavage map of Tn10, a transposon which encodes tetracycline resistance. Journal of Bacteriology 137 , 681-685.

Kondo, E. \& Mitsuhashi, S. (1964). Drug resistance of enteric bacteria. IV. Active transducing bacteriophage $\mathrm{P} 1 \mathrm{CM}$ produced by the combination of $\mathrm{R}$ factor with bacteriophage P1. Journal of Bacteriology $88,1266-1276$. 
Kondo, E., Harada, K. \& Mitsuhashi, S. (1962). Drug resistance of enteric bacteria, 12. Transduction of the transmissible drug resistance factor by bacteriophage P1 kc. Japanese Journal of Experimental Medicine 32, 139-147.

LANE, D. \& ChandLer, M. (1977). Mapping of the drug resistance genes carried by the r-determinant of the R 100-1 plasmid. Molecular and General Genetics 157, 17-23.

Machattie, L. A. \& Jackowski, J. B. (1977). Physical structure and deletion effects of the chloramphenicol resistant element $\operatorname{Tn} 9$ in phage lambda. In $D N A$ Insertion Elements, Plasmids and Episomes, pp. 219228. Edited by A. I. Bukhari, J. A. Shapiro \& S. L. Adhya, New York: Cold Spring Harbor Laboratory.

MARCOLI, R., IIDA, S. \& BICKLE, T. A. (1980). The DNA sequence of an IS1-flanked transposon coding for resistance to chloramphenicol and fusidic acid. FEBS Letters 110, 11-14.

MaXAM, A. M. \& GilberT, W. (1977). A new method for sequencing DNA. Proceedings of the National Academy of Sciences of the United States of America 74, 560-564.

Meyer, J., IIdA, S. \& Arber, W. (1980). Does the insertion element ISI transpose preferentially into A + T-rich DNA segments? Molecular and General Genetics 178, 471-473.

Meynell, E. \& DatTa, N. (1967). Mutant drugresistant factors of high transmissibility. Nature, London 214, 885-887.

Miki, T., EASTON, M. \& Rownd, R. (1978). Mapping of the resistance genes of the R plasmid NR1. Molecular and General Genetics 158, 217-224.

Novick, R. P., Clowes, R. C., Cohen, S. N., Curtiss, R., III, DatTa, N. \& Falkow, S. (1976). Uniform nomenclature for bacterial plasmids: a proposal. Bacteriological Reviews 40, 168-189.

Oнтsuвo, H. \& Oнтsubo, E. (1977). Repeated DNA sequences in plasmids, phages and bacterial chromosomes. In DNA Insertion Elements, Plasmids, and
Episomes, pp. 49-64. Edited by A. I. Bukhari, J. A. Shapiro \& S. L. Adhya. New York: Cold Spring Harbor Laboratory.

Oнтsubo, H. \& Oнтsubo, E. (1978). Nucleotide sequence of an insertion element, IS1. Proceedings of the National Academy of Sciences of the United States of America 75, 615-619.

Rownd, R., Nakaya, R. \& Nakamura, A. (1966). Molecular nature of the drug-resistance factors of the Enterobacteriaceae. Journal of Molecular Biology 17, 376-393.

ScotT, J. R. (1968). Genetic studies on bacteriophage P1. Virology 36, 564-574.

Shaw, W. V., Pachman, L. C., Burleigh, B. D., Dell, A., Morris, H. R. \& Hartley, B. S. (1979). Primary structure of a chloramphenicol acetyltransferase specified by R plasmids. Nature, London $\mathbf{2 8 2}$, $870-872$.

Soberon, X., Covarrubias, L. \& Bolivar, F. (1980). Construction and characterization of new cloning vehicles. IV. Deletion derivatives of pBR322 and pBR325. Gene 9, 287-305.

SOUTHERn, E. M. (1975). Detection of specific sequences among DNA fragments separated by gel electrophoresis. Journal of Molecular Biology 98, 503-517.

Timmis, K. N., Cabello, F. \& Cohen, S. N. (1978). Cloning and characterization of Eco RI and HindIII restriction endonuclease-generated fragments of antibiotic resistance plasmids R6-5 and R6. Molecular and General Genetics 162, 121-137.

VölKer, T., IIDA, S. \& BiCKLE, T. A. (1982). A single gene coding for resistance to both fusidic acid and chloramphenicol. Journal of Molecular Biology 154, 417-425.

WoOD, W. B. (1966). Host specificity of DNA produced by Escherichia coli: bacterial mutations affecting the restriction and modification of DNA. Journal of Molecular Biology 16, 118-133. 